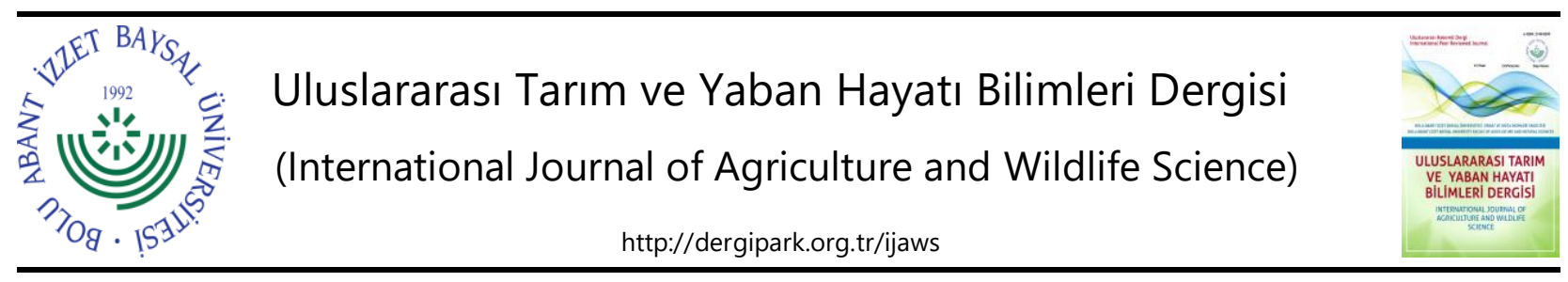

Araştırma Makalesi

\title{
Mikrobiyal Gübre Uygulamasının Marul ve Beyaz Baş Lahanada Çimlenme ve Fide Gelişimi Üzerine Etkileri
}

\author{
Beyhan Kibar \\ Bolu Abant İzzet Baysal Üniversitesi, Ziraat Fakültesi, Bahçe Bitkileri Bölümü, Bolu \\ Geliş tarihi (Received): 29.09.2020 \\ Kabul tarihi (Accepted): 06.11.2020
}

\begin{abstract}
Anahtar kelimeler:
Brassica oleracea var. capitata

L., Lactuca sativa L., mikrobiyal gübre, fide, büyüme
\end{abstract}

Özet. Günümüzde çevreye verilen öneme paralel olarak, tarımsal üretimde kullanılan kimyasal gübreler yerine alternatif olarak mikroorganizmaların kullanımı gittikçe önem kazanmaktadır. Bu çalışma, ülkemizde en çok üretilen kışlık sebzeler arasında yer alan marul ve beyaz baş lahanada mikrobiyal gübre uygulamasının çimlenme ve fide gelişimi üzerine etkilerini belirlemek amacıyla yapılmıştır. Bitkisel materyal olarak Green Wave marul çeşidi ve Bayraklı-85 beyaz baş lahana çeşidi kullanılmıştır. Çalışmada EM.5 isimli ticari mikrobiyal gübrenin 5 farklı dozu $(0,5,10,15$ ve $20 \mathrm{~mL} \mathrm{~L}$ 1) uygulanmıştır. Araştırma sonucunda mikrobiyal gübre dozları arasında incelenen özellikler bakımından önemli farklılıklar bulunmuştur. Araştırmadan elde edilen bulgulara göre mikrobiyal gübrenin marulda çimlenme oranı, fide boyu, fide kuru ağırlığı, kök kuru ağılığı ve kuru madde oranını; beyaz baş lahanada ise fide boyu, fide yaş ağırlığı ve kuru madde oranını kontrole göre önemli oranda artırdığı tespit edilmiştir. Genel olarak, mikrobiyal gübre uygulamalarının tohum çimlenmesi ve fide büyüme parametreleri üzerinde olumlu etkilerinin olduğu belirlenmiştir. Mikrobiyal gübre dozları değerlendirildiğinde, $15 \mathrm{~mL} \mathrm{~L}^{-1}$ uygulamasının hem marulda hem de beyaz baş lahanada çimlenme ve fide gelişimi üzerinde daha etkili olduğu tespit edilmiştir. Kontrol uygulaması ile karşılaştıııldığında, $15 \mathrm{~mL} \mathrm{~L}^{-1}$ uygulaması marulda fide boyunu \%35.71 oranında ve beyaz baş lahana ise fide yaş ağırığını \%38.18 oranında artırmıştır. Mikrobiyal gübre uygulamasının marul ve beyaz baş lahanada çimlenme ve fide gelişimini artırmada alternatif bir uygulama yöntemi olarak başarılı bir şekilde kullanılabileceği sonucuna varılmıştır.

\section{Effects of Microbial Fertilizer Application on Germination and Seedling Growth in Lettuce and White Head Cabbage}

\section{Keywords:}

Brassica oleracea var. capitata L., Lactuca sativa L., microbial fertilizer, seedling, growth

\begin{abstract}
Nowadays, in parallel with the importance given to environment, the use of microorganisms as an alternative to chemical fertilizers used in agricultural production is becoming increasingly important. This study was carried out to determine effects of microbial fertilizer application on germination and seedling growth in lettuce and white head cabbage, which are among the most produced winter vegetables in our country. Green Wave lettuce variety and Bayraklı-85 white head cabbage variety were used as herbal material. In the study, 5 different doses of commercial microbial fertilizer named EM.5 $\left(0,5,10,15\right.$ and $\left.20 \mathrm{~mL} \mathrm{~L}^{-1}\right)$ were evaluated. As a result of research, significant differences were found among microbial fertilizer doses in terms of properties examined. According to findings obtained from research, it was determined that microbial fertilizer was significantly increased germination rate, seedling height, seedling dry weight, root dry weight and dry matter rate in lettuce; seedling height, seedling fresh weight and dry matter rate in white head cabbage compared to the control. In general, it has been detected that microbial fertilizer applications have positive effects on seed germination and seedling growth parameters. When microbial fertilizer doses were evaluated, it was determined that $15 \mathrm{~mL} \mathrm{~L}^{-1}$ application was more effective on germination and seedling growth in both lettuce and white head cabbage. When compared to the control, $15 \mathrm{~mL} \mathrm{~L}^{-1}$ application increased seedling height by $35.71 \%$ in lettuce and seedling fresh weight by $38.18 \%$ in white head cabbage. It was concluded that microbial fertilizer application can be used successfully as an alternative application method to increase germination and seedling growth in lettuce and white head cabbage.
\end{abstract}




\section{GíRiş}

Marul (Lactuca sativa L.), Compositae (Asteraceae) familyasında yer alan tek yıllık bir serin iklim sebzesidir. Marulun anavatanının Avrupa, Asya ve Kuzey Afrika ülkelerini içine alan geniş bir alan olduğu kabul edilmektedir (Vural ve ark., 2000; Günay, 2005). Dünyada uzun yıllardan beri tarımı yapılan ve sevilerek tüketilen marul, yılın tamamında pazarlarda ve marketlerde bulunabilmektedir (Aybak, 2002). Sebze olarak taze yaprakları değerlendirilen marul, yüksek ticari öneme sahip türler arasında yer almaktadır (Eşiyok, 2012). Marul form zenginliği en fazla olan sebzeler arasındadır. Ülkemizin hemen hemen her yerinde açıkta veya örtü altında yetiştirilebilmektedir. Yetişme periyodu 2-3 ay gibi kısa süreli olup, değişik mevsimlere uygun olarak ıslah edilmiş çeşitlerle arka arkaya bütün yıl boyunca üretim yapılması mümkündür. Her mevsim yetiştirilebildiğinden üreticisine yüksek ekonomik gelir sağlayan bir sebzedir (Yıldııım ve ark., 2015). Genellikle taze olarak tüketilen ve insan beslenmesinde önemli bir yere sahip olan marul önemli bir vitamin ve mineral kaynağıdır (Günay, 2005). iç̧erdiği yüksek miktardaki A ve C vitamini, nişasta içermemesi, yağ oranı ve kalorisinin çok düşük olmasından dolayı iyi bir diyet yiyeceğidir. Ayrıca marul antioksidan özelliği yüksek olan bir sebze türüdür (Şalk ve ark., 2008). Ülkemizde 2019 yılı verilerine göre 91.439 da alanda 215.728 ton göbekli marul, 95.303 da alanda 198.491 ton kıvırcık marul ve 29.119 da alanda 85.547 ton aysberg marul üretimi olmak üzere toplam marul üretimi 499.766 ton olarak tespit edilmiştir (TÜik, 2020).

Beyaz baş lahana (Brassica oleracea var. capitata L.), Brassicaceae (Cruciferae) familyasına ait olup tüm dünyada yaygın olarak yetiştirilen ve tüketilen önemli sebze türlerinden biridir (Singh ve ark., 2009). Dünya üzerinde geniş bir yayılım alanı gösteren lahananın anavatanının Kuzey Avrupa ülkeleri, Baltık Denizi kıyıları ve Akdeniz ülkeleri olduğu kabul edilmektedir (Monteiro ve Lunn, 1998; Vural ve ark., 2000). Serin iklim sebzesi olan beyaz baş lahana ilk yıl sebze olarak kullanılan başı oluştururken, ikinci yılda çiçeklenerek tohum bağlamaktadır. İnsan beslenmesi ve sağlığına önemli katkıda bulunan beyaz baş lahana protein, mineraller (kalsiyum, potasyum, magnezyum, fosfor, sodyum ve demir), vitaminler (A, B1, B2, B12, C ve K), lif ve andioksidanlar yönünden oldukça zengindir (Kopsell ve ark., 2004; Swarup, 2006; Hounsome ve ark., 2009; Singh ve ark., 2009; 2010). Değişik şekillerde tüketilebilen beyaz baş lahana çiğ olarak salatalarda kullanılabildiği gibi sarmalık, turşuluk ve yemeklik olarak da değerlendirilmektedir. Beyaz baş lahana ülkemizde, özellikle Karadeniz Bölgesi'nde yoğun bir şekilde yetiştirilen ve tüketiciler tarafından yüksek talep gören bir sebzedir. Ülkemizde sonbahar ve kış döneminde yetiştiriciliği yapılan beyaz baş lahananın ekonomik önemi oldukça yüksektir. Türkiye, 2019 yılı verilerine göre 137.114 da alanda 567.622 ton üretim ile dünyada önemli lahana üreticisi ülkeler içerisinde yer almaktadır (TÜiK, 2020).

Hızla artan dünya nüfusunun gıda ihtiyaçlarının karşılanabilmesi tarımsal üretimi artırmakla mümkündür. Günümüzde, tarımsal üretimi artırmak amacıyla mevcut tarım alanlarını genişletme imkanlarının sınırlı olması, birim alandan elde edilen ürün miktarının artırımasını gerekli kılmaktadır (Midmore, 1993). Birim alandan daha fazla verim almak için özellikle 20. yüzyılın başından itibaren tüm dünyada yoğun olarak ve bilinçsizce kimyasal gübre kullanılmış ve bu kimyasal gübrelerin toprak ve çevreye verdiği zararlar göz ardı edilmiştir. Aşırı miktarlarda kullanılan bu kimyasal gübreler bitkilerde verim ve kaliteyi artırmasına rağmen, toprak yapısında bozulmalara, topraktaki toksik maddelerin artmasına, toprakta bulunan mikroorganizmaların faaliyetlerinin azalmasına ve mevcut biyolojik dengenin bozulmasına neden olmaktadır (Topbaş ve ark., 1998; Chen ve ark., 2001; Vessey, 2003; Sönmez ve ark., 2008; Alagöz ve ark., 2020). Böylece hem insan sağlığı açısından ve hem de tarımın sürdürülebilirliği açısından istenmeyen bir durum oluşabilmektedir. Aşııı ve bilinçsiz kimyasal gübre uygulamaları sonucu bozulan doğal dengenin yeniden kurulabilmesi için insana ve çevreye dost üretim sistemlerini içeren, kimyasal tarım ilaçları ve gübrelerin kullanımını en aza indirgeyen uygulamaların tarımsal üretimde kullanılmasına intiyaç vardır (Zengin, 2007). Çevre dostu üretim tekniklerinde gübreleme programlarında kullanılan alternatif metotlardan birisi de mikrobiyal gübrelemedir.

Bitkiler için gerekli olan bitki besin elementlerinin sağlanmasında ve biyolojik yolla yarayışlı hale gelmesinde rol oynayan canlı mikroorganizmaların tarımsal üretimde kullanılmak üzere hazırlanan ticari formülasyonları "mikrobiyal gübre" veya "biyogübre" olarak tanımlanmaktadır (Özbay ve ark., 2018). Mikrobiyal gübreleme ise bu doğal mikroorganizmaların çoğaltılarak uygun bir formülasyonda bitkilere verilmesidir. Günümüzde tarımsal üretimde kullanılan kimyasal gübreler yerine alternatif olarak mikroorganizmaların kullanımı gittikçe önem kazanmaktadır. Dünyada gelişmiş ve gelişmekte olan birçok ülkede, temiz çevre ve sağlıklı bitkisel üretim için biyolojik veya mikrobiyal gübre formülasyonları elde edilmesi amacıyla yoğun çalışmalar yapılmaktadır (Vessey, 2003). Mikrobiyal gübre olarak kullanılan yararlı mikroorganizmalar genellikle Bacillus spp., Pseudomonas spp., Azotobacter spp., Trichoderma spp., Rhizobium spp., Azospirillum spp ve Saccharomyces spp.'den seçilmektedir (Özbay ve ark., 2015). Bitki ile toprak mikroorganizmaları arasında olması gereken dengenin yeniden kurulmasında mikrobiyal gübreleme oldukça önemlidir. Mikrobiyal gübreler tarımsal üretimde birçok amaçla kullanılmaktadır. Bu çevre dostu gübreler birçok bitkide bitki gelişimi ve verimin artıııması, bazı toprak kaynaklı hastalıkların kontrol 
edilmesi, hastalık ve zararılıara dayanıklıı̆ın artıııması, bitkilerin besin elementi alımının artırılması, organik artıkların ayrıştıııması, toprak yapısının düzeltilmesi, su tutma kapasitesinin artıııması ve verimliliğinin iyileştirilmesi gibi alanlarda kullanılmaktadır (Ozbay ve Newman, 2004; Brewer ve Larkin, 2005; Irmak ve ark., 2011). Mikrobiyal gübreler, özellikle sürdürülebilir tarımın en büyük destekleyicisi olma özelliği taşımaktadır.

Sebze üretiminde başarıyı etkileyen en önemli faktörlerden birisi, iyi bir tohum ve bundan elde edilecek kaliteli fidedir. Kaliteli fide ile üretime başlamak hem verimi artırmak hem de kaliteli ürün elde etmek için büyük önem taşımaktadır. Ülkemizde sebze üretim miktarının artışına paralel olarak son yıllarda sebze yetiştiriciliğinde hazır fide üretimi ve kullanımı da hızla yaygınlaşmaktadır. Türkiye'de toplam fide üretiminin 3.5 milyar civarında olduğu bildirilmektedir (Yanmaz ve ark., 2015). Çoğunlukla sıcak iklim sebzelerinde fide kullanımı yaygın olmasına rağmen, serin iklim sebzelerinden marul ve lahana grubu sebzelerde de kullanım oranı oldukça yüksektir. Kaliteli bir fide; hastalık ve zararlılardan ari, pişkin ve kuru maddece zengin, kalın ve kuvvetli bir gövdeye, koyu yeşil yapraklara, canlı ve kuvvetli bir kök yapısına sahip olmalıdır (Vural ve ark., 2000). Fide kalitesini etkileyen en önemli faktörlerden birisi, fidenin yetiştirildiği ortamdaki bitki besin maddelerinin yarayışlı miktarlarıdır. Faydalı mikroorganizmaların kullanımı ile ekolojik denge korunarak kaliteli fide elde etmek mümkündür. Nitekim, farkı sebze türlerinde yapılan çalışmalar mikrobiyal gübre uygulamasının tohum çimlenmesi, fide büyümesi ve kalitesi üzerinde önemli etkilerinin olduğunu ortaya koymuştur (Yedidia ve ark. 2001; Bal ve Altintas, 2008; Azarmi ve ark., 2011; Kumar, 2017; ikiz, 2019).

Bu çalışma, marul ve beyaz baş lahanada farklı dozlarda mikrobiyal gübre uygulamalarının çimlenme ve fide gelişimi üzerine etkilerini araştırmak amacıyla yürütülmüştür.

\section{MATERYAL VE METOT}

Araştırma, Ocak 2020-Mart 2020 tarihleri arasında, Bolu Abant İzzet Baysal Üniversitesi Ziraat Fakültesi Bahçe Bitkileri Bölümü'ne ait laboratuvar ve iklim odasında yürütülmüştür. Çalışmada bitkisel materyal olarak Green Wave marul (Lactuca sativa L.) çeşidi ve Bayraklı-85 beyaz baş lahana (Brassica oleracea var. capitata L.) çeşitlerinin tohumları kullanılmıştır. Mikrobiyal gübre olarak ise özel bir firma (EM Agriton) tarafından üretilen EM.5 isimli ticari mikrobiyal gübre kullanılmışır. EM.5 çeşitli mikroorganizma gruplarının (fotosentez bakterisi, laktik asit bakterisi, mayalar, aktinomisetler ve küfler) karışımından oluşan bir sıvı mikrobiyal gübredir. Çalışmada EM.5 mikrobiyal gübrenin 5 farklı dozu $\left(0,5,10,15\right.$ ve $\left.20 \mathrm{~mL} \mathrm{~L}^{-1}\right)$ ele alınmış olup, 0 dozu kontrol olarak kullanılmıştır.

\section{Çimlendirme Çalışması}

Çalışmada öncelikle marul ve beyaz baş lahana tohumlarında mikrobiyal gübre uygulamasının çimlenme üzerine etkisinin belirlenmesi amacıyla laboratuvarda çimlendirme denemesi yapılmıştır. Deneme, tesadüf parselleri deneme desenine göre 4 tekerrürlü ve her tekerrürde 50 tohum olacak şekilde, $22^{\circ} \mathrm{C}$ sıcaklığa sahip çimlendirme kabininde karanlık koşullarda 10 gün süreyle yürütülmüştür. Çimlenme öncesinde tohumların \%3'lük sodyum hipoklorit $(\mathrm{NaClO})$ ile yüzeysel sterilizasyonu yapılmış ve daha sonra tohumlar saf su ile yıkanmışır. Çimlendirme için $9 \mathrm{~cm}$ çapındaki petri kapları kullanıımıştır. Petri kapları kullanılmadan önce etüvde $170{ }^{\circ} \mathrm{C}^{\prime}$ de 4 saat steril edilmiştir (Muhammad ve Hussain, 2010). Petri kapları içerisindeki filtre kağıtları üzerine her bir petride 50 tohum olacak şekilde tohumlar yerleştirilmiştir. Daha sonra her bir petri kabına çalışmada ele alınan mikrobiyal gübre dozlarına ait $\left(0,5,10,15\right.$ ve $\left.20 \mathrm{~mL} \mathrm{~L}^{-1}\right)$ çözeltilerden $10 \mathrm{~mL}$ ilave edilmiş ve petrilerin kapağı kapatılarak tohumlar çimlendirme kabininde çimlenmeye bırakılmıştır. Kuruyan petri kaplarına eşit miktarda aynı dozlarda çözeltiden ilave edilmiştir. Tohumlarda 1-2 mm uzunluğunda kökçüğün görülmesi çimlenme için yeterli olarak kabul edilmiştir. Çimlenen tohumlar her gün aynı saatte sayılmış ve ortamdan uzaklaştırılmıştır. Çimlendirme testi sonunda (10. gün) çimlenme oranı (\%) belirlenmiştir. Çimlenme oranı (ÇO)'nın hesaplanmasında, ÇO = [Çimlenen tohum sayısı/Toplam tohum sayısı] x 100 formülü kullanılmıştır (Özbay ve ark., 2018).

\section{Fide Çalışması}

Fide denemesi, $21 \pm 1{ }^{\circ} \mathrm{C}$ ortam sıcaklığı, \%50-55 nem ve 14 saat ışı/ $/ 10$ saat karanlık periyoda sahip iklim odasında yürütülmüştür. Deneme tesadüf parselleri deneme desenine göre 3 tekerrürlü olarak kurulmuştur. Her tekerrürde 10 fide olacak şekilde toplam her iki türden $(2 \times 5 \times 3 \times 10) 300$ fide yetiştirilmiştir. Marul ve beyaz baş lahana tohumları 3:1 oranında ( $\mathrm{v} / \mathrm{v}$ ) torf:perlit karışımı içeren $200 \mathrm{~mL}$ 'lik beyaz plastik bardaklara ekilmiştir. Tohum ekimi tamamlandıktan sonra sulama yapılmıştır. Çıkışlardan sonra her bardakta bir bitki olacak şekilde seyreltilmiştir. Mikrobiyal gübre uygulaması gerçek yapraklar çıktıktan sonra 5 gün aralıklarla toplam 3 kez yapılmıştır. Çalışmada ele alınan dozlarda hazırlanan $\left(0,5,10,15\right.$ ve $\left.20 \mathrm{~mL} \mathrm{~L}^{-1}\right)$ mikrobiyal gübre solüsyonları her bir uygulamada bitki başına $10 \mathrm{~mL}$ olacak şekilde yaprakların altına ve üstüne iyice ıslanacak şekilde püskürtülerek mikrobiyal gübreleme gerçekleştirilmiştir. Kontrol grubunda herhangi bir mikrobiyal gübre uygulaması 
yapılmamıştır. Yetiştirme periyodu boyunca nem durumu kontrol edilerek gerekli görüldüğünde sulama yapılmıştır. Fidelere herhangi bir kimyasal gübre veya ilaç uygulanmamıştır. Tohum ekiminden 45 gün sonra deneme sonlandırılmış ve mikrobiyal gübre dozlarının etkilerini belirlemek amacıyla fideler topraktan kökleri ile sökülerek fide büyüme parametreleri belirlenmiştir. Fide çalışmasında fide boyu $(\mathrm{cm})$, gövde çapı $(\mathrm{mm})$, fide yaş ağırlığı (g), fide kuru ağırlığı (g), kök uzunluğu (cm), kök yaş ağırlığı (g), kök kuru ağırlığı (g), yaprak sayısı (adet bitki $\left.{ }^{-1}\right)$, kuru madde miktarı (\%), klorofil değeri (spad), renk $\left(L^{*}, a^{*}, b^{*}, C^{*}\right.$ ve $\left.h^{\circ}\right), p H$ ve elektriksel iletkenlik (EC, $\mu S$ $\mathrm{cm}^{-1}$ ) tespit edilmiştir. Çalışmada fide boyu ve kök uzunluğu cetvel yardımıyla ölçülerek; fide yaş ağırlığı ve kök yaş ağırlığı hassas terazide tartılarak; fide kuru ağırlığı ve kök kuru ağırlığı etüvde $65^{\circ} C^{\prime}$ de sabit ağırlığa ulaşana kadar kurutulduktan sonra hassas terazide tartılarak; gövde çapı dijital kumpasla ölçülerek; yaprak sayısı fidelerde oluşan gerçek yapraklar sayılarak; kuru madde oranı Kılıç ve ark. (1991)'e göre; klorofil miktarı tam olarak gelişmiş yapraklarda klorofil ölçer (Apogee Chlorophyll Concentration Meter, MC-100) ile; renk $\left(L^{*}, a^{*}, b^{*}, C^{*}\right.$ ve $\left.h^{\circ}\right)$ tam olarak gelişmiş yapraklarda renk ölçer cihazı (3NH NR60CP) ile; $\mathrm{pH}$ ve elektriksel iletkenlik değerleri bitkinin toprak üstü kısımlarında pH metre (Thermo Scientific, Orion Star A111) ve EC metre (Thermo Scientific, Orion Star A212) kullanılarak belirlenmiştir.

\section{istatistiksel Değerlendirme}

Araştırma sonucunda elde edilen veriler JMP 13.2 istatistik programı kullanılarak varyans analizine tabi tutulmuştur. İncelenen özellikler bakımından istatistiki olarak önemli bulunan ortalamalar arasındaki farklılıklar Tukey HSD (Tukey's Honestly Significant Difference Test) çoklu karşılaştırma testi ile belirlenmiştir.

\section{BULGULAR VE TARTIŞMA}

Marulda farklı dozlarda mikrobiyal gübre uygulamalarının çimlenme ve fide büyüme parametreleri üzerine etkileri Çizelge 1'de verilmiştir. Çimlenme oranı, fide boyu, kök kuru ağırlığı, kuru madde oranı, EC ve pH bakımından mikrobiyal gübre dozları arasındaki farklııklar $\mathrm{P}<0.01$ düzeyinde önemli; fide kuru ağırlığı ve renk özelliklerinden $b^{*}$ değeri bakımından ise mikrobiyal gübre dozları arasındaki farklııılar $P<0.05$ düzeyinde önemli bulunmuştur. Diğer taraftan, gövde çapı, fide yaş ağırlığı, kök uzunluğu, kök yaş ağırlığı, yaprak sayısı, klorofil değeri, $L^{*}, a^{*}, C^{*}$ ve $h^{\circ}$ renk değerleri yönünden çalışmada ele alınan mikrobiyal gübre dozları arasındaki farklılıklar önemsiz bulunmuştur.

Çalışmada marul tohumlarında çimlenme oranı \%64.33-74.00 arasında değişmiş̧tir. En yüksek çimlenme oranı $15 \mathrm{~mL} \mathrm{~L}^{-1}$ mikrobiyal gübre uygulamasında belirlenmiştir. En düşük çimlenme oranları istatistiksel olarak aralarında fark olmayan diğer mikrobiyal gübre dozları ile kontrol uygulamasında saptanmıştır. Mikrobiyal gübre uygulamalarından kontrole göre daha yüksek çimlenme oranları elde edilmiş olup, mikrobiyal gübrenin çimlenme üzerinde olumlu etkisinin olduğu tespit edilmiştir. Çalışmada, $15 \mathrm{~mL} \mathrm{~L}^{-1}$ uygulaması mikrobiyal gübre uygulamasının yapılmadığı kontrole $\left(0 \mathrm{~mL} \mathrm{~L}^{-1}\right)$ göre çimlenme oranını \%15.03 oranında artırmıştır. Bu çalışmanın sonuçlarına benzer olarak daha önce yapılan çalışmalarda mikrobiyal gübre uygulamalarının kavunda (Kaveh ve ark., 2011), marulda (Özbay ve ark., 2015), domateste (Kumar, 2017), ıspanakta (Özbay ve ark., 2018) ve tatlı mısırda (Altunlu ve ark., 2019) çimlenme oranını kontrole göre önemli oranda artırdığı bildirilmiştir. Çimlenme üzerindeki bu olumlu etkinin mikrobiyal gübre uygulaması yapılan tohumlardaki oksin gibi hormonların artışından kaynaklandığı belirtilmektedir (Bakonyi ve ark., 2013).

Çimlenme oranında olduğu gibi fide boyu bakımından da en yüksek değer $5.70 \mathrm{~cm}$ ile $15 \mathrm{~mL} \mathrm{~L}^{-1}$ mikrobiyal gübre uygulamasında saptanmış olup, onu istatistiksel olarak aralarında fark olmayan $20 \mathrm{~mL} \mathrm{~L}^{-1}$ uygulaması (5.50 $\mathrm{cm}$ ) izlemiştir. En düşük fide boyu ise $4.20 \mathrm{~cm}$ ile kontrolde gözlenmiştir. Mikrobiyal gübre uygulamalarının kontrole göre fide boyunda önemli artışlar sağladığı tespit edilmiştir. Nitekim, mikrobiyal gübre uygulamasının dozlara bağlı olarak fide boyunu kontrole göre \%7.14-35.71 oranında artırdığı saptanmıştır. Benzer şekilde, Azarmi ve ark. (2011), Kumar (2017) ve İkiz (2019) domateste mikrobiyal gübrenin kontrole göre fide boyunu önemli oranda artırdığını bildirmişlerdir.

Mikrobiyal gübre uygulamaları ile marul fidelerinde fide kuru ağırlığı önemli düzeyde etkilenmiş, en yüksek fide kuru ağırlığı istatistiksel olarak aynı grupta yer alan 10,15 ve $20 \mathrm{~mL} \mathrm{~L}^{-1}$ uygulamalarında $(0.16 \mathrm{~g})$, en düşük fide kuru ağırlığı ise 0 ve $5 \mathrm{~mL} \mathrm{~L}^{-1}$ uygulamalarında $(0.15 \mathrm{~g})$ gözlenmiştir. Çalışmada mikrobiyal gübrenin fide kuru ağırlığını olumlu yönde etkilediği, özellikle 10,15 ve $20 \mathrm{~mL} \mathrm{~L}^{-1}$ uygulamalarının kontrole göre fide kuru ağırlığını önemli oranda artırdığı tespit edilmiştir. Bu çalışmanın sonuçlarına benzer şekilde, domates fidelerinde mikrobiyal gübrelemenin kontrole göre fide kuru ağırlığını önemli düzeyde artırdığı tespit edilmiştir (Azarmi ve ark., 2011). Diğer taraftan, marul, domates ve hıyar fidelerinde vejetatif aksam (yaprak+gövde) kuru ağırlığı bakımından kontrol ve mikrobiyal gübreleme arasında önemli bir fark bulunmamıştır (ikiz, 2019). 
Çizelge 1. Marulda farklı dozlarda mikrobiyal gübre uygulamalarının çimlenme ve fide büyüme parametreleri üzerine etkileri. Table 1. Effects of microbial fertilizer applications at different doses on germination and seedling growth parameters in lettuce.

\begin{tabular}{|c|c|c|c|c|c|c|}
\hline \multirow{2}{*}{$\begin{array}{l}\text { Mikrobiyal } \\
\text { gübre dozları } \\
\left(\mathrm{mL} \mathrm{L}^{-1}\right)\end{array}$} & \multicolumn{6}{|c|}{ Özellik } \\
\hline & $\begin{array}{l}\text { Çimlenme } \\
\text { oranı } \\
(\%) \\
\end{array}$ & $\begin{array}{l}\text { Fide boyu } \\
(\mathrm{cm})\end{array}$ & $\begin{array}{l}\text { Gövde çapı } \\
(\mathrm{mm})\end{array}$ & $\begin{array}{l}\text { Fide yaş } \\
\text { ağırlığı } \\
\left(\mathrm{g} \text { bitki }^{-1}\right)\end{array}$ & $\begin{array}{l}\text { Fide kuru } \\
\text { ağırlığı } \\
\left(g_{\text {bitki }}^{-1}\right)\end{array}$ & $\begin{array}{l}\text { Kök } \\
\text { uzunluğu } \\
(\mathrm{cm})\end{array}$ \\
\hline 0 & $64.33 b^{\star \star}$ & $4.20 c^{* *}$ & $2.15^{\text {öd }}$ & $1.16^{\text {öd }}$ & $0.15 b^{\star}$ & $17.03^{\text {öd }}$ \\
\hline 5 & $67.00 \mathrm{~b}$ & $4.50 c$ & 2.18 & 1.17 & $0.15 b$ & 17.72 \\
\hline 10 & $68.67 b$ & $4.68 \mathrm{bc}$ & 2.32 & 1.22 & $0.16 a$ & 17.37 \\
\hline 15 & $74.00 \mathrm{a}$ & $5.70 a$ & 2.35 & 1.25 & $0.16 a$ & 17.30 \\
\hline 20 & $68.00 \mathrm{~b}$ & $5.50 \mathrm{ab}$ & 2.33 & 1.21 & $0.16 a$ & 17.28 \\
\hline $\begin{array}{l}\text { Mikrobiyal } \\
\text { gübre dozları } \\
\left(\mathrm{mL} \mathrm{L}^{-1}\right)\end{array}$ & $\begin{array}{l}\text { Kök yaş } \\
\text { ağırlığı } \\
\left.\text { (g bitki }^{-1}\right) \\
\end{array}$ & $\begin{array}{l}\text { Kök kuru } \\
\text { ağırlığı } \\
\left.\text { (g bitki }^{-1}\right) \\
\end{array}$ & $\begin{array}{l}\text { Yaprak } \\
\text { sayısı }\end{array}$ & $\begin{array}{l}\text { Kuru madde } \\
\text { oranı } \\
(\%)\end{array}$ & $\begin{array}{l}\text { Klorofil } \\
\text { (spad) }\end{array}$ & $\begin{array}{l}\text { EC } \\
\left(\mu S \mathrm{~cm}^{-1}\right)\end{array}$ \\
\hline 0 & $0.52^{\text {öd }}$ & $0.08 c^{* *}$ & $6.33^{\text {öd }}$ & $11.07 b^{* \star}$ & $17.15^{\text {öd }}$ & $43.23 a^{* *}$ \\
\hline 5 & 0.57 & $0.10 a$ & 6.33 & $11.56 b$ & 17.10 & $35.69 b$ \\
\hline 10 & 0.56 & $0.09 a b$ & 6.56 & $12.63 a$ & 17.55 & $32.13 c$ \\
\hline 15 & 0.55 & $0.09 a b$ & 6.78 & $12.75 a$ & 17.92 & $31.86 c$ \\
\hline 20 & 0.54 & $0.09 \mathrm{ab}$ & 6.41 & $11.48 b$ & 17.58 & $31.69 c$ \\
\hline $\begin{array}{l}\text { Mikrobiyal } \\
\text { gübre dozları } \\
\left(\mathrm{mL} \mathrm{L}^{-1}\right)\end{array}$ & $\mathbf{p H}$ & $\mathbf{L}^{*}$ & $a^{*}$ & $\mathbf{b}^{*}$ & $C^{*}$ & $h^{\circ}$ \\
\hline 0 & $6.39 a^{* \star}$ & $56.53^{\text {öd }}$ & $-14.31^{\text {öd }}$ & $36.30 b^{*}$ & $39.02^{\text {öd }}$ & $111.52^{\text {öd }}$ \\
\hline 5 & $6.33 b$ & 56.85 & -14.21 & $37.68 \mathrm{a}$ & 40.27 & 110.68 \\
\hline 10 & $6.31 b$ & 56.08 & -14.05 & $36.12 b$ & 38.77 & 111.26 \\
\hline 15 & $6.29 b c$ & 56.40 & -14.37 & $36.97 b$ & 39.66 & 111.57 \\
\hline 20 & $6.25 c$ & 56.08 & -14.59 & $36.51 b$ & 39.63 & 111.59 \\
\hline
\end{tabular}

**: $\mathrm{P}<0.01$ düzeyinde önemli, *: $\mathrm{P}<0.05$ düzeyinde önemli, öd: önemli değil, Aynı sütunda aynı harfle gösterilen ortalamalar arasındaki fark önemli değildir.

Çalışmada ele alınan mikrobiyal gübre dozlarına bağlı olarak marul fidelerinde kök kuru ağırlığı 0.08-0.10 g arasında değişmiş olup, en yüksek $5 \mathrm{~mL} \mathrm{~L}^{-1}$ uygulamasında, en düşük ise kontrol uygulamasında gözlenmiştir. Kök kuru ağırlığı yönünden de mikrobiyal gübre uygulamalarının kontrole göre önemli artışlar sağladığı tespit edilmiştir. Elde edilen bu sonuçlar, önceki çalışmalar ile uyumlu bulunmuştur. Yedidia ve ark. (2001), mikrobiyal gübrelemenin hıyar fidelerinde kontrol bitkileri ile karşılaştııldığında kök kuru ağırlığında önemli artışlar meydana getirdiğini belirtmiştir. Benzer şekilde, Akkuş (2011) Ispanakta ve kerevizde, Özbay ve ark. (2015) marulda, Özbay ve ark. (2018) ıspanakta mikrobiyal gübrenin kontrole göre kök kuru ağırlı̆ını artırdığını bildirmişlerdir.

Marul fidelerinde kuru madde oranı bakımından en yüksek değerler istatistiksel olarak aynı grupta yer alan 15 ve $10 \mathrm{~mL} \mathrm{~L}^{-1}$ uygulamalarında (sırasıyla \%12.75 ve 12.63) belirlenmiştir. En düşük kuru madde oranları ise istatistiksel olarak aralarında fark olmayan kontrol, 20 ve $5 \mathrm{~mL} \mathrm{~L}^{-1}$ uygulamalarında (sırasıyla \%11.07, 11.48 ve 11.56) tespit edilmiştir. Tüm mikrobiyal gübre dozlarında kontrolden daha yüksek kuru madde oranları elde edilmiştir. Kontrol uygulaması ile karşılaştııılığında, $15 \mathrm{~mL} \mathrm{~L}^{-1}$ mikrobiyal gübre uygulamasında kuru madde oranı bakımından \%15.18 oranında bir artış meydana gelmiştir. Bulgularımız mikrobiyal gübreleme ile kuru madde oranının arttığını bildiren diğer araştırıııların (Özbay ve ark., 2015; 2018; Ikiz, 2019) sonuçlarıyla paralellik göstermektedir.

EC seviyesi bakımından çalışmada ele alınan gübre dozları incelendiğinde, kontrol uygulaması $42.23 \mu \mathrm{S} \mathrm{cm}^{-1}$ ile ilk sırada yer almıştır. En düşük EC değerleri ise istatistiksel olarak aynı grupta yer alan 20,15 ve $10 \mathrm{~mL} \mathrm{~L}^{-1}$ uygulamalarında (sırasıyla 31.69, 31.86 ve $32.13 \mu \mathrm{S} \mathrm{cm}^{-1}$ ) gözlenmiştir. Mikrobiyal gübre dozlarının artması ile birlikte, EC değeri azalma göstermiştir. Katgıc ve ark. (2019) tarafından marulda yapılan çalışmada kontrol ve mikrobiyal gübreleme arasında EC değeri bakımından önemli bir fark bulunmamıştır.

Marul fidelerinde $\mathrm{pH}$ değeri 6.25-6.39 arasında değişmiş̧tir. Kontrol uygulamasında pH değerinin mikrobiyal gübre uygulamalarından daha yüksek olduğu belirlenmiştir. Buna karşılık, en düşük pH değeri $20 \mathrm{~mL} \mathrm{~L}^{-1}$ uygulamasında bulunmuştur. EC değerinde olduğu gibi mikrobiyal gübre dozu arttıkça, pH değerlerinde bir düşüş meydana gelmiştir. Çubuklu (2011) domateste yaptığı çalışmada pH değeri bakımından kontrol ve mikrobiyal gübre arasındaki farkın önemsiz olduğunu bildirmiş̧ir.

Marul fidelerinde en yüksek $b^{*}$ değeri $5 \mathrm{~mL} \mathrm{~L}^{-1}$ uygulamasında (37.68) tespit edilmiştir. En düşük $b^{*}$ değerleri ise istatistiksel olarak aynı grupta yer alan kontrol ile 10,15 ve $20 \mathrm{~mL} \mathrm{~L}^{-1}$ uygulamalarında saptanmıştır. Renk parametrelerinden $b^{*}$ değeri sarıdan (pozitif) maviye (negatif) renk değişimlerini belirtmektedir. Marulda renk 
kalite açısından önemli unsurlar arasında yer almaktadır. Farklı dozlarda uygulanan mikrobiyal gübrenin marul fidelerinde $L^{*}, a^{*}, C^{*}$ ve $h^{\circ}$ renk değerlerinde meydana getirdiği değişiklik istatistiki olarak önemli görülmemiş olup, sırasıyla 56.08-56.85, (-14.59) - (-14.05), 38.77-40.27 ve 110.68-111.59 arasında bulunmuştur. İkiz (2019) mikrobiyal gübre uygulamasının fide kalitesine etkilerini araştırdığı çalışmada marul fidelerinde $L^{*}, a^{*}, b^{*} C^{*}$ ve $h^{\circ}$ değerleri bakımından kontrol ve mikrobiyal gübreleme arasında önemli bir farkın olmadığını bildirmiştir. Katgıcı ve ark. (2019)'nın marulda yaptıkları çalışmada mikrobiyal gübrenin $L^{*}$ ve $C^{*}$ renk değerlerinde meydana getirdiği değişiklik önemli bulunmamış olup, $h^{\circ}$ renk değerinin kontrolden daha yüksek olduğu tespit edilmiştir.

Çalışmada ele alınan mikrobiyal gübre dozlarına bağlı olarak marul fidelerinde gövde çapı, fide yaş ağırlığı, kök uzunluğu, kök yaş ağılığı, yaprak sayısı ve klorofil değeri sırasıyla 2.15-2.35 mm, 1.16-1.25 g, 17.03-17.72 cm, 0.52-0.57 g, 6.33-6.78, 17.10-17.92 spad arasında değişiklik göstermiştir. İstatistiksel olarak farklılık göstermemekle birlikte gövde çapı, fide yaş ağırlığı, kök uzunluğu ve kök yaş ağırlığı bakımından mikrobiyal gübre uygulamalarından kontrole göre daha yüksek değerler elde edilmiştir. Aynı şekilde, yaprak sayısı ve klorofil değeri yönünden de 10, 15 ve $20 \mathrm{~mL} \mathrm{~L}^{-1}$ mikrobiyal gübre uygulamalarının kontrole göre artış sağladığı tespit edilmiştir. Çubuklu (2011) tarafından domateste, Katgıcı ve ark. (2019) tarafından marulda yapılan çalışmalarda mikrobiyal gübrenin klorofil değeri üzerinde önemli bir etkisinin olmadığı bildirilmiştir. Yapılan başka bir çalışmada domates ve hıyar fidelerinde gövde çapı bakımından kontrol ve mikrobiyal gübreleme arasında önemli bir fark bulunmamıştır (Ikiz, 2019). Domates fidelerinde mikrobiyal gübreleme ile gövde çapı, yaprak sayısı ve klorofil içeriğinin kontrol uygulamasına kıyasla arttığı tespit edilmiştir (Azarmi ve ark., 2011). Ispanak, marul, tere ve rokada yapılan çalışmalarda mikrobiyal gübreleme ile yaprak sayısı ve klorofil içeriğinin kontrole göre önemli oranda arttığı ifade edilmiştir (Özbay ve ark., 2010; 2015; 2018). Mikrobiyal gübrelemede kullanılan mikroorganizmaların etkinliği bitki türü, yetiştirme ortamı, yetiştirme sezonu, çevre şartları ve depolama şartları gibi birçok faktöre bağlı olarak önemli derecede değişebilmektedir (Buyer ve ark., 2002). Buna bağlı olarak da mikrobiyal gübreleme ile ilgili çalışmalarda birbirinden farklı sonuçlar elde edilebilmektedir. Mikrobiyal gübre uygulamalarında gübrenin etkisinin istenilen düzeye ulaşabilmesi için toprakların $\mathrm{pH}$, nem, organik madde gibi mikroorganizmaların yaşamını etkileyen özelliklerinin kontrol edilmesi gerekmektedir (Karaçal ve Tüfenkçi, 2010).

Araştırmadan elde edilen bulgulara göre mikrobiyal gübrenin marulda çimlenme oranı, fide boyu, fide kuru ağırlığı, kök kuru ağılığı ve kuru madde oranı üzerinde olumlu etkilerinin olduğu tespit edilmiştir. Mikrobiyal gübre dozları değerlendirildiğinde, $15 \mathrm{~mL} \mathrm{~L}^{-1}$ mikrobiyal gübre uygulamasının çimlenme ve fide gelişimi üzerinde daha etkili olduğu belirlenmiştir.

Çizelge 2'de görüldüğü gibi beyaz baş lahanada, fide boyu, fide yaş ağırlı̆̆ı, kök kuru ağırlığı, EC, pH ve hº renk değeri bakımından mikrobiyal gübre dozları arasındaki farklııklar $\mathrm{P}<0.01$ düzeyinde önemli; kuru madde oranı ile $b^{*}$ ve $C^{*}$ renk değerleri bakımından ise mikrobiyal gübre dozları arasındaki farklııklar $P<0.05$ düzeyinde önemli bulunmuştur. Buna karşıık, çimlenme oranı, gövde çapı, fide kuru ağırlığı, kök uzunluğu, kök yaş ağırlığı, yaprak sayısı, klorofil değeri ile L* ve a* renk değerleri yönünden mikrobiyal gübre dozları arasındaki farklıııların önemsiz olduğu tespit edilmiştir.

Fide boyu çalışmada ele alınan mikrobiyal gübre dozlarına bağlı olarak $6.02-7.81 \mathrm{~cm}$ arasında değişiklik göstermiştir. En yüksek fide boyu istatistiksel olarak aralarında fark bulunmayan 15,20 ve $10 \mathrm{~mL} \mathrm{~L}^{-1}$ mikrobiyal gübre uygulamaları ile kontrol uygulamasında tespit edilmiştir. Diğer taraftan, en düşük fide boyu $5 \mathrm{~mL} \mathrm{~L}^{-1}$ uygulamasında gözlenmiştir. Çalışmada 10, 15 ve $20 \mathrm{~mL} \mathrm{~L}^{-1}$ uygulamalarının kontrole göre fide boyunu önemli ölçüde artırdığı belirlenmiştir. $15 \mathrm{~mL} \mathrm{~L}^{-1}$ uygulamasında fide boyu kontrole göre \%13.35 oranında artmıştır. Farklı sebze türlerinde yapılan çalışmalarda da mikrobiyal gübrelemenin bitki boyunu artırdığı bildirilmiştir (Özbay ve ark., 2010; Çubuklu, 2011; Özbay ve ark., 2015; 2018; Altunlu ve ark., 2019).

Çalışmada ele alınan gübre dozları incelendiğinde, fide yaş ağırı̆ı̆ı bakımından $15 \mathrm{~mL} \mathrm{~L}^{-1}$ uygulaması $1.52 \mathrm{~g}$ ile ilk sırada yer almış olup, onu istatistiksel olarak aralarında fark bulunmayan 20 ve $10 \mathrm{~mL} \mathrm{~L}^{-1}$ uygulamaları izlemiştir. En düşük fide yaş ağırlığı ise istatistiksel olarak aynı grupta yer alan $5 \mathrm{ml} \mathrm{L}^{-1}$ uygulaması ile kontrolde (sırasıyla 1.03 ve $1.10 \mathrm{~g}$ ) gözlenmiştir. Fide yaş ağırlığı yönünden de 10,15 ve $20 \mathrm{~mL} \mathrm{~L}^{-1}$ mikrobiyal gübre uygulamalarının kontrolden daha yüksek değerlere sahip olduğu tespit edilmiştir. Kontrol uygulaması ile karşılaştırıldığında, $15 \mathrm{~mL}$ $\mathrm{L}^{-1}$ uygulaması fide yaş ağırlığında \%38.18 oranında bir artış sağlamıştır. Elde edilen bu sonuçlar, önceki çalışmalar ile uyumlu bulunmuştur. Marul, domates ve hıyar fidelerinde mikrobiyal gübrelemenin vejetatif aksam (yaprak+gövde) yaş ağırlığını kontrole göre önemli oranda artırdığı tespit edilmiştir (İkiz, 2019). Bal ve Altintas (2008) mikrobiyal gübre uygulanan marul fidelerinde yaş ağırlığın kontrol bitkilerine göre önemli ölçüde arttığını belirlemişlerdir. 
Çizelge 2. Beyaz baş lahanada farklı dozlarda mikrobiyal gübre uygulamalarının çimlenme ve fide büyüme parametreleri üzerine etkileri.

Table 2. Effects of microbial fertilizer applications at different doses on germination and seedling growth parameters in white head cabbage.

\begin{tabular}{|c|c|c|c|c|c|c|}
\hline \multirow{2}{*}{$\begin{array}{l}\text { Mikrobiyal } \\
\text { gübre dozları } \\
\left(\mathrm{mL} \mathrm{L}^{-1}\right)\end{array}$} & \multicolumn{6}{|c|}{ Özellik } \\
\hline & $\begin{array}{l}\text { Çimlenme } \\
\text { oranı } \\
(\%)\end{array}$ & $\begin{array}{l}\text { Fide boyu } \\
(\mathrm{cm})\end{array}$ & $\begin{array}{l}\text { Gövde çapı } \\
(\mathrm{mm})\end{array}$ & $\begin{array}{l}\text { Fide yaş } \\
\text { ağırlığı } \\
\left(g_{\text {bitki }}{ }^{-1}\right)\end{array}$ & $\begin{array}{l}\text { Fide kuru } \\
\text { ağırlığı } \\
\left(g_{\text {bitki }}{ }^{-1}\right)\end{array}$ & $\begin{array}{l}\text { Kök } \\
\text { uzunluğu } \\
\text { (cm) }\end{array}$ \\
\hline 0 & $87.33^{\text {öd }}$ & $6.89 a b^{* *}$ & $1.75^{\text {öd }}$ & $1.10 b^{* *}$ & 0.19 öd & $16.30^{\text {öd }}$ \\
\hline 5 & 86.00 & $6.02 b$ & 1.61 & $1.03 b$ & 0.14 & 16.28 \\
\hline 10 & 89.67 & $7.07 a$ & 1.64 & 1.29ab & 0.22 & 16.26 \\
\hline 15 & 91.00 & 7.81a & 1.81 & $1.52 \mathrm{a}$ & 0.25 & 16.20 \\
\hline 20 & 88.00 & $7.34 a$ & 1.78 & $1.35 \mathrm{ab}$ & 0.22 & 16.11 \\
\hline $\begin{array}{l}\text { Mikrobiyal } \\
\text { gübre dozları } \\
\left(\mathrm{mL} \mathrm{L}^{-1}\right)\end{array}$ & $\begin{array}{l}\text { Kök yaş } \\
\text { ağırlığı } \\
\left.\text { (g bitki }^{-1}\right)\end{array}$ & $\begin{array}{l}\text { Kök kuru } \\
\text { ağırlığı } \\
\left.\text { (g bitki }^{-1}\right)\end{array}$ & $\begin{array}{l}\text { Yaprak } \\
\text { sayısı }\end{array}$ & $\begin{array}{l}\text { Kuru madde } \\
\text { oranı } \\
(\%) \\
\end{array}$ & $\begin{array}{l}\text { Klorofil } \\
\text { (spad) }\end{array}$ & $\begin{array}{l}\text { EC } \\
\left(\mu S \mathrm{~cm}^{-1}\right)\end{array}$ \\
\hline 0 & $0.24^{\text {öd }}$ & $0.05 a^{* *}$ & $3.44^{\text {öd }}$ & $16.46 b^{*}$ & $38.13^{\text {öd }}$ & $72.59 a^{* *}$ \\
\hline 5 & 0.22 & $0.05 a$ & 3.44 & $16.05 b$ & 38.18 & $40.96 c$ \\
\hline 10 & 0.20 & $0.04 a b$ & 3.56 & $17.34 a$ & 38.43 & $46.33 b c$ \\
\hline 15 & 0.19 & $0.03 b$ & 3.67 & $17.33 a$ & 38.48 & $51.43 b$ \\
\hline 20 & 0.18 & $0.03 b$ & 3.56 & $17.32 \mathrm{a}$ & 38.17 & $53.93 b$ \\
\hline $\begin{array}{l}\text { Mikrobiyal } \\
\text { gübre dozları } \\
\left(\mathrm{mL} \mathrm{L}^{-1}\right)\end{array}$ & $\mathbf{p H}$ & $\mathbf{L}^{*}$ & $a^{*}$ & $\mathbf{b}^{*}$ & $C^{*}$ & $\mathbf{h}^{\circ}$ \\
\hline 0 & $6.36 c^{\star \star}$ & $55.59^{o ̈ d}$ & $-7.63^{\text {öd }}$ & $9.93 b^{*}$ & $12.54 b^{*}$ & $127.60 a^{* *}$ \\
\hline 5 & $6.17 d$ & 54.03 & -9.07 & $14.11 \mathrm{a}$ & $16.80 \mathrm{a}$ & $122.72 \mathrm{ab}$ \\
\hline 10 & $6.48 c$ & 54.23 & -8.53 & $14.18 a$ & $16.57 a$ & $121.14 b$ \\
\hline 15 & $6.81 b$ & 54.45 & -9.33 & 13.57ab & $16.49 a$ & $124.56 \mathrm{ab}$ \\
\hline 20 & $7.13 a$ & 52.82 & -6.52 & $11.40 \mathrm{ab}$ & $13.17 b$ & $118.53 b$ \\
\hline
\end{tabular}

**: $\mathrm{P}<0.01$ düzeyinde önemli, *: P<0.05 düzeyinde önemli, öd: önemli değil, Aynı sütunda aynı harfle gösterilen ortalamalar arasındaki fark önemli değildir.

Beyaz baş lahana fidelerinde kök kuru ağırlığı 0.03-0.05 g arasında değişiklik göstermiştir. En yüksek kök kuru ağırlığı istatistiksel olarak aynı grupta yer alan kontrol ile 5 ve $10 \mathrm{~mL} \mathrm{~L}^{-1}$ mikrobiyal gübre uygulamalarında belirlenirken, en düşük kök kuru ağırığı 15 ve $20 \mathrm{~mL} \mathrm{~L}^{-1}$ uygulamalarında saptanmıştır. Kök kuru ağırlığı ile ilgili olarak elde edilen bu bulgular farklı sebze türlerinde mikrobiyal gübrenin kök kuru ağırlığını kontrole göre önemli oranda artırdığını bildiren önceki bazı çalışmalarla (Yedidia ve ark., 2001; Akkuş, 2011; Özbay ve ark., 2015) farklılık göstermektedir. Diğer taraftan, İkiz (2019) domates, hıyar ve marul fidelerinde kök kuru ağırlığı bakımından kontrol ve mikrobiyal gübreleme arasında fark olmadığını bildirmiştir.

Beyaz baş lahana fidelerinde kuru madde oranı bakımından en yüksek değerler istatistiksel olarak aralarında fark olmayan 10, 15 ve $20 \mathrm{~mL} \mathrm{~L}^{-1}$ uygulamalarında (sırasıyla \%17.34, 17.33 ve 17.32) gözlenmiş, en düşük değerler ise $5 \mathrm{~mL} \mathrm{~L}^{-1}$ uygulaması ile kontrolde (sırasıyla \%16.05 ve 16.46) tespit edilmiştir. Çalışmada 10,15 ve $20 \mathrm{~mL} \mathrm{~L}^{-1}$ uygulamaları ile kontrole göre kuru madde oranında önemli düzeyde artış sağlanmıştır. Özbay ve ark. (2010) rokada mikrobiyal gübrelemenin kontrole göre kuru madde içeriğini artırdığını, terede ise kuru madde içeriğinin mikrobiyal gübrelemede kontrolden daha düşük bulunduğunu bildirmişlerdir.

Beyaz baş lahana fidelerinde EC seviyesi incelendiğinde, kontrolde $\left(72.59 \mu \mathrm{S} \mathrm{cm}^{-1}\right)$ mikrobiyal gübre uygulamalarına göre önemli derecede daha yüksek olduğu tespit edilmiştir. En düşük EC değeri $5 \mathrm{~mL} \mathrm{~L}^{-1}$ uygulamasında $\left(40.96 \mu \mathrm{S} \mathrm{cm}^{-1}\right)$ belirlenmiş olup, artan mikrobiyal gübre dozuna paralel olarak EC değerleri de artış göstermiş̧tir. Kontrol uygulamasında EC değerinde $5 \mathrm{~mL} \mathrm{~L}^{-1}$ mikrobiyal gübre uygulamasına göre yaklaşık 1.8 kat artış görülmüştür. Beyaz baş lahana fidelerindeki EC değerlerinde gübre dozlarının etkisinin yüksek olduğu belirlenmiştir. Katgıcı ve ark. (2019) marulda yaptıkları çalışmada mikrobiyal gübrenin EC değerini etkilemediğini bildirmişlerdir.

Beyaz baş lahana fidelerinde pH değerinin 6.17-7.13 arasında değiştiği tespit edilmiştir. EC değerinde olduğu gibi artan mikrobiyal gübre dozuna paralel olarak pH seviyesinde önemli seviyede artış meydana gelmiş ve çalışmada kullandığımız en yüksek gübre dozu olan $20 \mathrm{~mL} \mathrm{~L}^{-1}$ uygulamasında pH seviyesi en yüksek bulunmuştur. En düşük pH değeri ise $5 \mathrm{~mL} \mathrm{~L}^{-1}$ uygulamasında saptanmıştır. Katgıcı ve ark. (2019) marulda yaptıkları çalışmada $\mathrm{pH}$ değerinin mikrobiyal gübrelemede kontrolden daha yüksek olduğunu bildirmişlerdir. 
Çalışmada ele alınan mikrobiyal gübre dozlarına bağlı olarak beyaz baş lahana fidelerinde $b^{\star}$ değeri 9.93-14.18 arasında değişmiş olup, en yüksek mikrobiyal gübre uygulamalarında $\left(5,10,15\right.$ ve $\left.20 \mathrm{~mL} \mathrm{~L}^{-1}\right)$, en düşük ise kontrolde gözlenmiştir. $C^{*}$ değeri bakımından 5, 10 ve $15 \mathrm{~mL} \mathrm{~L}^{-1}$ mikrobiyal gübre uygulamaları ilk sırada yer alırken, kontrol ve $20 \mathrm{~mL} \mathrm{~L}^{-1}$ uygulamasının ise en düşük $\mathrm{C}^{*}$ renk değerlerine sahip olduğu tespit edilmiştir. $C^{*}$ değeri büyüdükçe rengin doygunluğu artmaktadır. Rengin niteliğini belirten $\mathrm{h}^{\circ}$ değerinin $118.53\left(20 \mathrm{~mL} \mathrm{~L}^{-1}\right.$ uygulaması) - 127.60 (kontrol) arasında değiştiği bulunmuştur. Çalışmada $h^{\circ}$ değerinin sarı $\left(90^{\circ}\right)$ ve yeşil $\left(180^{\circ}\right)$ renk arasında olduğu belirlenmiştir. Beyaz baş lahana fidelerinde $L^{*}$ ve $a^{*}$ renk değerleri farklı dozlarda mikrobiyal gübre uygulamalarından istatistiksel olarak önemli düzeyde etkilenmemiş olup, L* ve a* renk değerleri sırasıyla 52.82-55.59 ve (-9.33) - (-6.52) arasında bulunmuştur. Bu çalışmada elde edilen bulgulara benzer şekilde, İkiz (2019) domates fidelerinde $b^{*}, C^{*}$ ve $h^{\circ}$ renk değerlerinin mikrobiyal gübre ve kontrol arasında önemli farklılık gösterdiğini bildirmiştir. Araştıııcı ayrıca domates fidelerinde $b^{*}$ ve $C^{*}$ renk değerlerinin kontrolde mikrobiyal gübrelemeden daha düşük olduğunu belirtmiştir.

Beyaz baş lahana fidelerinde çimlenme oranı, gövde çapı, fide kuru ağırlığı, kök uzunluğu, kök yaş ağırlığı, yaprak sayısı ve klorofil değeri çalışmada ele alınan mikrobiyal gübre dozlarına bağlı olarak sırasıyla \%86.00-91.00, 1.61-1.81 mm, 0.14-0.25 g, 16.11-16.30 cm, 0.18-0.24 g, 3.44-3.67 ve 38.13-38.48 spad arasında değişiklik göstermiştir. İstatistiksel olarak farklılık göstermemekle beraber klorofil değeri bakımından mikrobiyal gübre uygulamalarından kontrole göre daha yüksek değerler elde edilmiştir. Aynı şekilde, çimlenme oranı, fide kuru ağırlı̆ı ve yaprak sayısı yönünden de 10,15 ve $20 \mathrm{~mL} \mathrm{~L}^{-1}$ mikrobiyal gübre uygulamalarının kontrole göre artış sağladığı tespit edilmiştir. Bu çalışmada elde edilen bulgulara benzer olarak daha önce yapılan çalışmalarda (Azarmi ve ark., 2011; ikiz, 2019) mikrobiyal gübre uygulamalarının farkı sebze türlerinde çimlenme oranı üzerinde önemli etkisinin olmadığı bildirilmiştir. Domateste ve marulda yapılan çalışmalarda mikrobiyal gübrenin klorofil değeri üzerinde önemli bir etkisinin olmadığı bildirilmiştir (Çubuklu, 2011; Katgıcı ve ark., 2019). Diğer taraftan, farklı araştırıcılar (Özbay ve ark., 2010; Akkuş, 2011; Özbay ve ark., 2015) mikrobiyal gübrelemenin kontrol ile karşılaştııılığında klorofil içeriğini önemli oranda artırdığını ifade etmişlerdir. Altintas ve Bal (2008), soğanda mikrobiyal gübrenin yaprak sayısı üzerinde önemli bir etkisinin olmadığını bildirmişlerdir. İkiz (2019) domates ve hıyar fidelerinde gövde çapı bakımından kontrol ve mikrobiyal gübreleme arasında önemli bir fark bulunmadığını belirtmiştir. Azarmi ve ark. (2011) domates fidelerinde mikrobiyal gübreleme ile gövde çapı, yaprak sayısı ve klorofil içeriğinin kontrol uygulamasına kıyasla arttığını tespit etmişlerdir.

Elde edilen sonuçlara göre mikrobiyal gübrenin beyaz baş lahanada fide boyu, fide yaş ağırlığı ve kuru madde oranı üzerinde olumlu etkilerinin olduğu tespit edilmiştir. Mikrobiyal gübre dozları değerlendirildiğinde, $15 \mathrm{~mL} \mathrm{~L}$ ${ }^{1}$ mikrobiyal gübre uygulamasının çimlenme ve fide gelişimi üzerinde daha etkili olduğu belirlenmiştir.

\section{SONUÇ}

Bu çalışmada, ülkemizde en çok üretilen kışık sebzeler arasında yer alan marul ve beyaz baş lahanada farklı dozlarda mikrobiyal gübre uygulamalarının çimlenme ve fide gelişimi üzerine etkileri incelenmiştir. Araştırma sonucunda mikrobiyal gübrenin marulda çimlenme oranı, fide boyu, fide kuru ağırlığı, kök kuru ağırlığı ve kuru madde oranını; beyaz baş lahanada ise fide boyu, fide yaş ağırlığı ve kuru madde oranını kontrole göre önemli oranda artırdığı tespit edilmiştir. Buna ilave olarak, istatistiksel olarak farklılık göstermemekle birlikte marulda gövde çapı, fide yaş ağırlığı, kök uzunluğu ve kök yaş ağırlığı bakımından; beyaz baş lahanada ise klorofil değeri bakımından mikrobiyal gübre uygulamalarından kontrole göre daha yüksek değerler elde edilmiştir. Genel olarak, mikrobiyal gübre uygulamalarının tohum çimlenmesi ve fide büyüme parametrelerine pozitif yönde etkilerinin olduğu belirlenmiştir. Mikrobiyal gübrenin farklı dozları kendi arasında değerlendirildiğinde, özellikle $15 \mathrm{~mL} \mathrm{~L}^{-1}$ mikrobiyal gübre uygulamasının hem marulda hem de beyaz baş lahanada çimlenme ve fide gelişimi üzerinde daha etkili olduğu saptanmıştır. Kontrol uygulaması ile karşılaştıııldığında, $15 \mathrm{~mL} \mathrm{~L}^{-1}$ uygulaması marulda çimlenme oranını \%15.03, fide boyunu \%35.71 ve kuru madde oranını \%15.18 oranında; beyaz baş lahana ise fide boyunu \%13.35 ve fide yaş ağırlığını \%38.18 oranında artırmıştır. Mikrobiyal gübre uygulamasının marul ve beyaz baş lahanada çimlenme ve fide gelişimini artırmada alternatif bir uygulama yöntemi olarak başarılı bir şekilde kullanılabileceği ve $15 \mathrm{~mL} \mathrm{~L}^{-1}$ dozunun uygun doz olarak önerilebileceği sonucuna varılmıştır. Fide büyümesine ve kalitesine olan etkileri yanında uygulamanın insan ve çevre sağlığına duyarlı olması ve ayrıca organik fide üretiminde de kullanılabilecek olması mikrobiyal gübrelemenin önemini daha da artırmaktadır. Bununla birlikte, iklim odası koşullarında yapılan bu denemenin arazi koşullarında daha detaylı olarak yapılmasının elde edilen sonuçların yetiştirici ortamında kullanılması ve bu sonuçların etkilerinin paylaşılabilmesi için gerekli olduğu düşünülmektedir. 


\section{ÇIKAR ÇATIŞMASI}

Yazar olarak makalenin planlanması, yürütülmesi ve yazılması konusunda herhangi bir çıkar çatışması olmadığını beyan ederim.

\section{YAZAR KATKISI}

Yazar olarak makalenin planlanması, yürütülmesi ve yazımı tarafımca yapılmıştır.

\section{TEŞEKKÜR}

Bu çalışmanın yürütülmesinde yardımcı olan lisans öğrencileri Merve UYSAL ve Kübra Feyza KILIÇ'a teşekkür ederim.

\section{KAYNAKLAR}

Akkuş, F. (2011). Mikrobiyal ve inorganik gübre uygulamalarının tuz stresi altında yetiştirilen ıspanak (Spinacia oleracea) ve kök kerevizde (Apium graveolens) bitki gelişimi ve verim üzerine etkisi. Yüksek Lisans Tezi, Atatürk Üniversitesi, Fen Bilimleri Enstitüsü, Erzurum.

Alagöz, G., Özer, H., \& Pekşen A. (2020). Raised bed planting and green manuring increased tomato yield through improved soil microbial activity in organic cultivation. Biological Agriculture \& Horticulture, 36(3), 187-199.

Altintas, S., \& Bal, U. (2008). Effects of the commercial product based on Trichoderma harzianum on plant, bulb and yield characteristics of onion. Scientia Horticulturae, 116(2), 219-222.

Altunlu, H., Demiral, O., Dursun, O., Sönmez, M., \& Ergün, K. (2019). Mikrobiyal gübre uygulamasının tatı mısır (Zea mays L. var. saccharata) yetiştiriciliğinde bitki gelişimi ve verim üzerine etkileri. Atatürk Üniversitesi Ziraat Fakültesi Dergisi, 50(1), 32-39.

Azarmi, R., Hajieghrari, B., \& Giglou, A. (2011). Effect of Trichoderma isolates on tomato seedling growth response and nutrient uptake. African Journal of Biotechnology, 10(31), 5850-5855.

Aybak, H. Ç. (2002). Salata/Marul Yetiştiriciliği. Hasad Yayıncılılıı, İstanbul.

Bakonyi, N., Bott, S., Gajdos, E., Szabo, A., Jakab, A., Toth, A., Makleit, P. \& Veres, S. Z. (2013). Using biofertilizer to improve seed germination and early development of maize. Polish Journal of Environmental Studies, 22(6),1595-1599.

Bal, U., \& Altintas, S. (2008). Effects of Trichoderma harzianum on lettuce in protected cultivation. Journal Central Europen Agriculture, 9(1), 63-70.

Brewer, M. T., \& Larkin, R. P. (2005). Efficacy of several potential biocontrol organisms against Rhizoctonia solani on potato. Crop Protection, 24, 939-950.

Buyer, J. S., Roberts, D. P., \& Russek-Cohen, E. (2002). Soil and plant effects on microbial community structure. Canadian Journal of Microbiology, 48, 955-964.

Chen, S. K., Edwards, C. A., \& Subler, S. (2001). Effects of the fungicides benzomyl, captan and chlorothalonil on soil microbial activity and nitrogen dynamics in laboratory incubations. Soil Biology \& Biochemistry, 33, 1971-1980.

Çubuklu, Ö. (2011). Aşılı ve aşısız domates fideleri ile yapılan yetiştiricilikte mikrobiyal gübrenin (Trichoderma harzianum) verim ve kalite üzerine etkileri. Yüksek Lisans Tezi, Çanakkale Onsekiz Mart Üniversitesi, Fen Bilimleri Enstitüsü, Çanakkale.

Eşiyok, D. (2012). Kışılk ve Yazlık Sebze Yetiştiriciliği. Meta Basım. Bornova/izmir.

Günay, A. (2005). Sebze Yetiş̧iriciliği. Cilt II, İzmir.

Hounsome, N., Hounsome, B., Tomos, D., \& Jones, G. E. (2009). Changes in antioxidant compounds in white cabbage during winter storage. Postharvest Biology and Technology 52, 173-179.

Irmak, S., Cil, A. N., \& Cil, A. (2011). The effects of microbial fertilizer applications on yield and some yield elements of peanut in Çukurova Region in Turkey. Research Journal of Pharmaceutical, Biological and Chemical Sciences, 2(1), 880-888.

Ikiz, O. (2019). Bazı sebze türlerinde tohum ekim ortamına Trichoderma harzianum uygulamasının fide kalitesine etkileri. Yüksek Lisans Tezi, Ege Üniversitesi, Fen Bilimleri Enstitüsü, İzmir.

Karaçal, İ., \& Tüfenkçi, Ş. (2010). Bitki beslemede yeni yaklaşımlar ve gübre-çevre ilişkisi. Ziraat Mühendisliği VII. Teknik Kongresi, Ankara. 
Katgıcı, A., Türk, I.., Demir, H., \& Üçok, Z. (2019). Mikrobiyal gübrenin kıvırcık marulda verim ve kaliteye etkileri. II. Uluslararası Tarım ve Orman Kongresi, İzmir.

Kaveh, H., Jartoodeh, S. V., Aruee, H., \& Mazhabi, M. (2011). Would Trichoderma affect seed germination and seedling quality of two muskmelon cultivars, khatooni and qasri and increase their transplanting success? Journal of Biological \& Environmental Sciences, 5(15), 169-175.

Kılıç, O., Çapur, U., \& Görtay, Ş. (1991). Meyve ve Sebze Işleme Teknolojisi Uygulama Kılavuzu. Uludağ Üniversitesi Ziraat Fakültesi Ders Notları, Bursa.

Kopsell, D. E., Kopsell, D. A., Lefsrud, M. G., \& Curran, C. J. (2004). Variability in elemental accumulations among leafy Brassica oleracea cultivars and selections. Journal of Plant Nutrition, 27, 1813-1826.

Kumar, N. (2017). Occurrence and distribution of tomato diseases and evaluation of bio-efficacy of Trichoderma harzianum on growth and yield components of tomato. Nigerian Journal of Agriculture, Food and Environment, 13(2), 37-44.

Midmore, D. J. (1993). Agronomic modification of resource use and intercrop productivity. Field Crops Research, 34, $357-380$.

Monteiro, A., \& Lunn, T. (1998). Trends and perspectives of vegetable Brassica breeding world-wide. World Conference on Horticultural Research, Rome, Italy.

Muhammad, Z., \& Hussain, F. (2010). Effect of $\mathrm{NaCl}$ salinity on the germination and seedling growth of some medicinal plants. Pakistan Journal of Botany, 42(2), 889-897.

Ozbay, N., \& Newman, S. E. (2004). Effect of Trichoderma harzianum strains to colonize tomato roots and improve transplant growth. Pakistan Journal of Biological Sciences, 7, 253-257.

Özbay, N., Emrebaş, N., \& Akıncı, S. (2010). Topraksız ortamda roka ve tere yetiştiriciliğinde mikrobiyal gübre (Trichoderma harzianum, Kuen 1585) uygulamasının bitki gelişimi ve verimi üzerine etkileri. Ege Üniversitesi Ziraat Fakültesi Dergisi, Özel Sayı, 268-274.

Özbay, N., Demirkıran, A. R., \& Ergun, M. (2015). Mikrobiyal gübre (Trichoderma harzianum, KUEN 1585) uygulamasının marulda çimlenme, gelişme ve verim üzerine etkisi. Doğu Karadeniz II. Organik Tarım Kongresi, Rize, Türkiye.

Özbay, N., Ergun, M., \& Demirkıran, A. R. (2018). Ticari mikrobiyal gübre Sim Derma (Trichoderma harzianum, Kuen 1585) uygulamasının ıspanakta çimlenme, gelişme ve verim üzerine etkisi. Türk Tarım ve Doğa Bilimleri Dergisi, 5(4), $482-491$.

Singh B. K., Sharma S. R., \& Singh B. (2009). Heterosis for mineral elements in single cross-hybrids of cabbage (Brassica oleracea var. capitata L). Scientia Horticulturae, 122(1), 32-36.

Singh, B. K., Sharma, S. R., \& Singh, B. (2010). Variation in mineral concentrations among cultivars and germplasms of cabbage (Brassica oleracea var. capitata L.). Journal of Plant Nutrition, 33(1), 95-104.

Sönmez, İ, Kaplan, M., \& Sönmez, S. (2008). Kimyasal gübrelerin çevre kirliliği üzerine etkileri ve çözüm önerileri. Batı Akdeniz Tarımsal Araştırma Enstitüsü Derim Dergisi, 25(2), 24-34.

Swarup, V. (2006). Vegetable Science and Technology in India. Kalyani Publishers, New Delhi, India.

Şalk, A., Arın, L., Deveci, M., \& Polat, S. (2008). Özel Sebzecilik. Sevil Cilt Evi ve Matbaası, Tekirdağ.

Topbaş, M. T., Brohi, A. R., \& Karaman, M. R. (1998). Çevre Kirliliği. T.C. Çevre Bakanlığı Çevre Bakanlığı Yayını, Ankara.

TÜiK. (2020). Bitkisel üretim istatistikleri. http://www.tuik.gov.tr._Erişim tarihi: 10 Ağustos 2020.

Vessey, J. K. (2003). Plant growth promoting rhizobacteria as bio fertilizers. Plant and Soil, 255, 571-586.

Vural, H., Eşiyok, D., \& Duman, İ. (2000). Kültür Sebzeleri (Sebze Yetiştirme). Ege Üniversitesi Basımevi, İzmir.

Yanmaz, R., Duman, I., Yaralı, F., Demir, K., Sarıkamış, G., Sarı, N., Balkaya, A., Kaymak, H. Ç., Akan, S., \& Özalp, R. (2015). Sebze üretiminde değişimler ve yeni arayışlar. Türkiye Ziraat Mühendisliği VIII. Teknik Kongresi, Ankara.

Yedidia, I., Srivastva, A. K., Kapulnik, Y., \& Chet, I. (2001). Effect of Trichoderma harzianum on microelement concentrations and increased growth of cucumber plants. Plant and Soil, 235, 235-242.

Yıldırım, M., Bahar, E., \& Demireli, K. (2015). Farklı sulama suyu seviyelerinin serada yetiştirilen kıvırcık marulun (Lactuca sativa var. campania) verimi ve gelişimi üzerine etkileri. Çanakkale Onsekiz Mart Üniversitesi Ziraat Fakültesi Dergisi, 3(1), $29-34$.

Zengin, M. (2007). Organik Tarım. Hasad Yayıncılık Limited Şirketi, İstanbul. 